\title{
Decreased plasma fibrinolysis in patients with rheumatoid arthritis
}

\author{
J. J. F. BELCH, B. Mc ARDLE, R. MADHOK, K. McLAUGHLIN, H. A. CAPELL, \\ C. D. FORBES, ANDR. D. STURROCK
}

From the University Department of Medicine, Centre for Rheumatic Diseases, Royal Infirmary, Glasgow

SUMMARY We have investigated the fibrinolytic status of 56 patients with rheumatoid arthritis (RA). Plasma fibrinogen and plasminogen were significantly elevated. Levels of these two substrates, along with $\alpha_{2}$ macroglobulin and antithrombin III correlated with disease activity. Plasminogen activator (PA) activity was decreased in patients with severe disease. Twelve patients were given stanozolol, a fibrinolytic enhancing agent, for two months as a test for endothelial production of plasminogen activator. This caused a significant increase in blood plasminogen and PA activity. Five patients received a two-week course of stanozolol with joint aspiration before and after. Joint plasminogen levels were increased. We suggest that inadequate fibrinolysis occurs in $\mathrm{RA}$, and that this may contribute to some of the pathological features of the disease. It is possible to stimulate both blood and joint fibrinolysis by stanozolol. A more prolonged increase in plasminogen activator activity might decrease joint fibrin deposition, and stanozolol should be investigated as a therapeutic agent in RA.

An elevated plasma fibrinogen is a well recognised feature of active rheumatoid arthritis (RA), and the presence of large amounts of fibrin in the synovial fluid and membrane is also well documented in this disease. ${ }^{2}$ Normally the fate of fibrin, once it is formed, is related to its enzymatic degradation, which is mediated by plasmin. Plasmin is produced, when required, by cleavage of its inactive precursor protein plasminogen. The rate of this reaction is determined by the relative proportions of activators and inhibitors of fibrinolysis present. Plasminogen activator (PA) transforms plasminogen to plasmin and is therefore an activator of fibrinolysis, whereas $\alpha_{2}$ macroglobulin $\left(\alpha_{2} M\right)$ is an inhibitor of fibrinolysis.

Inflammation of the vascular endothelium, as may occur in RA, with subsequent endothelial damage might be expected to decrease the ability of the endothelium to produce PA. It has also been suggested that excessive fibrin deposition may be implicated in the loss of joint mobility and deformity seen in $\mathrm{RA},{ }^{3}$ and that an excess of deposition over removal may underlie some forms of chronic inflammation.

Accepted for publication 14 June 1984.

Correspondence to Dr J. J. F. Belch, University Department of Medicine, Royal Infirmary, 10 Alexandra Parade, Glasgow G31 2ER
Jasani suggests that intra-articular fibrin deposition may lead to the development of some of the joint manifestations of RA, including pannus formation and polymorph induced cartilage destruction. ${ }^{4}$

The fibrinolytic potential of RA patients has therefore been investigated by a number of workers. Unfortunately such studies have produced conflicting results. Fearnley et al. $^{5}$ and others ${ }^{3}$ suggested a decrease in whole blood fibrinolysis in RA, whereas other workers have found evidence to suggest an increased or normal fibrinolytic potential.

In an effort to clarify the situation the blood fibrinolytic status of 56 patients with RA of varying disease activity has been assessed and compared with that of normal population. RA patients with low fibrinolytic activity were then given stanozolol, a fibrinolytic enhancing agent which increases plasminogen and plasminogen activator levels. ${ }^{7}$ This drug can be used as a test of endothelial PA production and it can be determined whether it is possible to stimulate fibrinolysis in this disease.

\section{Patients and methods}

Fifty-six patients with classical or definite RA, as defined by American Rheumatism Association 
Table 1 Scoring of features used to assess disease activity

\begin{tabular}{lllllll}
\hline Score & $\begin{array}{l}\text { Morning } \\
\text { stiffness }(\text { min) }\end{array}$ & $\begin{array}{l}\text { Pain } \\
\text { scale }(\mathrm{cm})\end{array}$ & $\begin{array}{l}\text { Grip } \\
\text { strength } \\
(\text { mmHg) }\end{array}$ & $\begin{array}{l}\text { Articular } \\
\text { index }\end{array}$ & Hb (g/dl) & ESR (mm/h) \\
\hline 1 & 10 & $0-2 \cdot 4$ & 200 & 0 & $14 \cdot 1$ & $0-20$ \\
2 & $10-30$ & $2 \cdot 5-4 \cdot 4$ & $50-200$ & $1-7$ & $13-14$ & $21-45$ \\
3 & $31-120$ & $4 \cdot 5-6 \cdot 4$ & $21-49$ & $8-17$ & $10-12 \cdot 9$ & $46-80$ \\
4 & 120 & $6 \cdot 5-10$ & 20 & 18 & $9 \cdot 9$ & 81 \\
\hline
\end{tabular}

Mallya et al.: Serum C-reactive protein in $R A .^{7}$

criteria, were enrolled in the study after informed consent had been obtained. The mean age of the patients was 55 years (SD 7 years) and the mean duration of disease 9 (SD 5 years).

The patients were seen at the same time each day (between 9 and $11 \mathrm{am}$ ) after a standard light breakfast. Disease activity was assessed by measuring duration of morning stiffness (minutes), grip strength (mmHg, mean of three readings), Ritchie articular index, and the reading on a $10 \mathrm{~cm}$ visual analogue pain scale. Blood was sampled for haemoglobin estimation $(\mathrm{Hb}, \mathrm{g} / \mathrm{dl})$ and measurement of erythrocyte sedimentation rate $(E S R \mathrm{~mm} / \mathrm{h})$. Using the technique described by Mallya et al. ${ }^{8}$ we assigned a score of disease activity (range $1 \cdot 0-4 \cdot 0$ ) to each patient depending on the results of the above tests (Table 1).

In addition to $\mathrm{Hb}$ and ESR measurements blood was also drawn for estimation of plasma fibrinogen and fibrinolysis. For these tests blood was anticoagulated with $3 \cdot 8 \%$ trisodium citrate $(9: 1 \mathrm{v} / \mathrm{v})$. Plasma fibrinogen, ${ }^{9}$ plasminogen activity, ${ }^{10}$ and plasminogen activator activity ${ }^{11}$ assays were carried out in the standard fashion.

We also measured $\alpha_{2} \mathrm{M}$ (radioimmunodiffusion) ${ }^{12}$

Table 2 Disease activity in RA patients (mean $\pm S D$ )

\begin{tabular}{lc}
\hline Stiffness (min) & $110 \pm 84$ \\
Articular index & $20 \pm 11$ \\
Grip strength $(\mathrm{mmHg})$ & $90 \pm 30$ \\
Visual analogue $(\mathrm{cm})$ & $5 \cdot 7 \pm 2 \cdot 4$ \\
Hb $(\mathrm{G} / \mathrm{dl})$ & $11 \cdot 6 \pm 1 \cdot 4$ \\
ESR $(\mathrm{mm} \cdot \mathrm{h})$ & $56 \pm 29$ \\
Mallya score & $2 \cdot 8 \pm 0 \cdot 5$ \\
\hline
\end{tabular}

and antithrombin III (AT III) activity using a chromogenic substrate supplied by the Boehringer Corporation.

A group of 30 age and sex matched controls also underwent blood sampling for the above tests.

Twelve patients with severe RA (Mallya score $>2.5$ ) were then given a two-month course of stanozolol, an anabolic steroid with fibrinolytic enhancing effects, $5 \mathrm{mg}$ twice daily. Blood was sampled for estimation of plasminogen and PA activity before the tablets were started at 1 month, and again 2 months later.

A further subgroup of five patients who had knee effusions secondary to RA were given a two-week course of stanozolol at the same dose. Before the tablets were started, synovial fluid was withdrawn from the joint and measurement of plasminogen carried out. PA activity was not measured, as baseline measurements are undetectable in synovial fluid. ${ }^{4}$ Two weeks later a further sample of fluid was taken and the measurements repeated.

\section{Results}

CLINICAL

Table 2 gives the mean values for morning stiffness, articular index, grip strength, and visual analogue scale. Using the Mallya index, we obtained a mean score of $2 \cdot 8 \pm 0 \cdot 5$.

\section{B L OOD}

Baseline plasma fibrinogen and plasminogen were significantly elevated in RA patients when compared with the controls (Student's $t$ tests) (Table 3). The

Table 3 Fibrinogen and fibrinolysis in PA patients compared with control and correlated with disease activity (mean $\pm S D)$ : Spearman rank and Student's t test

\begin{tabular}{llll}
\hline Controls & $R A$ & $r$ value \\
\hline Fibrinogen $(\mathrm{g} / \mathrm{l})$ & $2 \cdot 8 \pm 0 \cdot 67$ & $4 \cdot 5 \pm 1 \cdot 1^{* *}$ & $0 \cdot 370^{*}$ \\
Plasminogen $(\mathrm{cu} / \mathrm{ml})$ & $2 \cdot 95 \pm 0 \cdot 81$ & $3 \cdot 87 \pm 0 \cdot 86^{* * *}$ & $0 \cdot 475^{* *}$ \\
$\alpha_{2}$ M $(\%)$ & $86 \cdot 1 \pm 21 \cdot 3$ & $93 \cdot 8 \pm 22 \cdot 8$ & $0 \cdot 380^{*}$ \\
AT III $(\%)$ & $94 \cdot 3 \pm 19 \cdot 3$ & $103 \cdot 21 \cdot 7$ & $0 \cdot 530^{* *}$ \\
\hline
\end{tabular}

$* 0.05, * *<0.01, * * *<0.001$. 
Table 4 Plasminogen and PA activity before and after stanzolol $( \pm S D)$

\begin{tabular}{llcc}
\hline Blood $(n=12)$ & Pre & 1 month & 2 months \\
\hline Pa activity $\left(\mathrm{mm}^{2}\right)$ & $50 \cdot 8 \pm 13$ & $62 \cdot 1 \pm 18$ & $64 \cdot 1 \pm 14^{* *}$ \\
Plasminogen $(\mathrm{CU} / \mathrm{ml})$ & $4 \cdot 0 \pm 0 \cdot 8$ & $4 \cdot 5 \pm 1 \cdot 1$ & $4 \cdot 7 \pm 1 \cdot 2^{*}$ \\
\hline Synovial fluid $(n=5)$ & Pre & 14 days & \\
Plasminogen $(\mathrm{cu} / \mathrm{ml})$ & $2 \cdot 5 \pm 0 \cdot 33$ & $3 \cdot 54 \pm 0 \cdot 92$ & \\
\hline
\end{tabular}

${ }^{*}<0.04,{ }^{* *}<0 \cdot 03$, paired $t$ test. $\mathrm{CU}=$ casein units.

levels of $\alpha_{2} \mathrm{M}$ and AI III also tended to be increased in RA, although the results did not reach statistical significance. All four measurements showed a significant positive correlation with disease activity as estimated by the Mallya score (Spearman rank correlation).

The results of PA activity are shown in Fig. 1. If patients with a Mallya score of equal to or less than $2 \cdot 5$ (i.e., those with moderate disease) are compared with those who have a score of greater than $2 \cdot 5$ (i.e., severe disease), it can be seen that patients with severe disease have significantly lower PA activity (Student's $t$ test, $\mathrm{p}<0.006$ ).

Sequential measurements of blood plasminogen

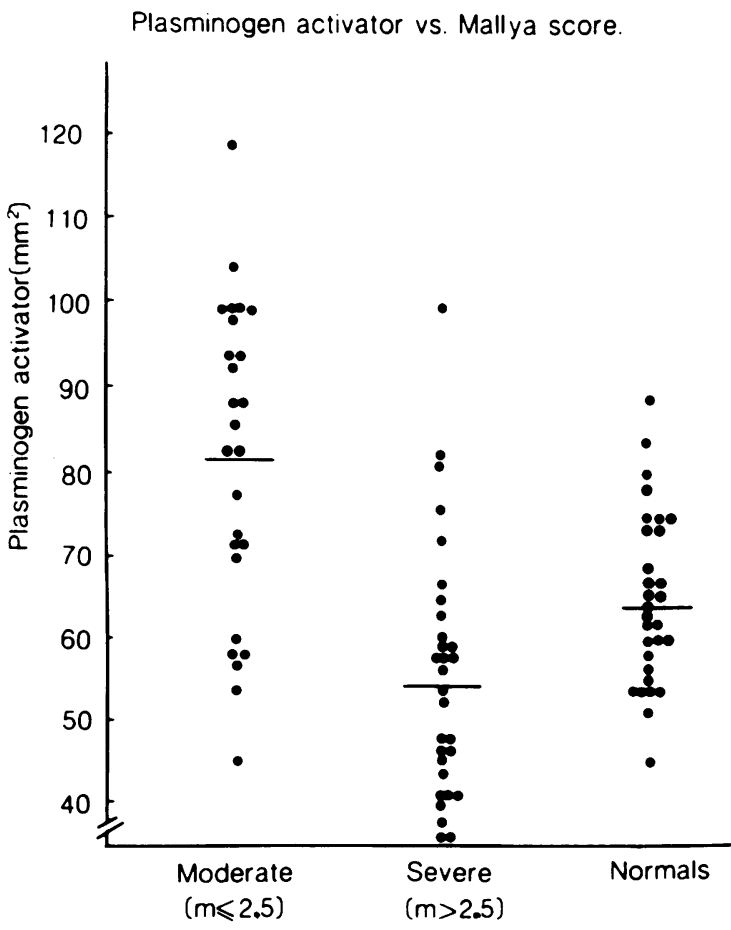

Fig. 1 Plasminogen activator activity in $R A$ patients and normal controls. and PA activity during stanozolol treatment showed a significant increase (paired $t$ test). Similarly plasminogen levels increased in synovial fluid (Table 4).

\section{Discussion}

From our results it can be seen that plasma levels of fibrinogen and plasminogen are significantly raised in patients with RA. Moreover, the levels of fibrinogen, plasminogen, and the inhibitors of fibrinolysis, $\alpha_{2} \mathrm{M}$, and AT III correlate with the degree of disease activity, being highest in those with severe disease. It is well recognised that fibrinogen is an acute phase protein and therefore an elevated level would be expected in active disease. There is also some evidence to suggest that $\alpha_{2} \mathrm{M}^{13}$ and AT III ${ }^{14}$ are likewise acute phase proteins, and our work would seem to support this.

However, the difference in PA activity seen in the patients with severe RA is not explicable on the basis of an acute phase reaction. Indeed, although the activity of PA is increased in moderate disease, it appears to be depressed in severe disease. This finding would suggest that either inadequate amounts of PA are being produced or that an inhibitor of PA is present. Experimental work supports the latter. ${ }^{34}$ Kwaan and Astrup ${ }^{15}$ suggest that the presence of inhibitors in fibrin clots results in delayed fibrin dissolution and enhanced formation of connective tissue. Fibrin is not normally found in joints, ${ }^{4}$ presumably because of continual fibrinolysis within the joint by blood vessel production of PA. It could be argued on the basis of these plasma results that this unusual build-up of fibrin in RA joints might be due to inadequate joint fibrinolysis. There is a correlation between levels of blood and synovial fluid protein,${ }^{3}$ and indeed fibrinolytic activity in blood and tissue may be related, since in tissues fibrinolysis is most marked round blood vessels. ${ }^{5}$ Experimental evidence in support of inadequate joint fibrinolysis has been provided by Berger $e t$ al. ${ }^{16}$ and van de Putte et al. ${ }^{3}$ The overall fibrinolytic potential of inflamed synovium is decreased, ${ }^{4}$ and it has been suggested that an inhibitor of fibrinolysis is present in areas where fibrin-like material is deposited.

This build-up of fibrin could lead to some of the 
joint manifestations of RA. It is known that fibrin produces a chronic inflammatory arthritis in rabbits when injected into previously sensitised animals, ${ }^{17}$ possibly via its action as an autoimmunogen or by the production of chemotactic derivatives which perpetuate the inflammation by neutrophils. Organisation of the fibrin deposits will ultimately lead to fibrosis of the synovial tissue. This scar tissue may interfere with cartilage nutrition, which depends on a functioning synovial membrane. Jasani ${ }^{4}$ provides experimental evidence to suggest that intraarticularly deposited fibrin may be responsible for swelling and proliferation of synovial lining and vascular endothelial cells, pannus formation, polymorphonuclear leucocyte-induced cartilage destruction, and the development of joint effusions. He also comments that its persistence, despite therapeutic use of maximally tolerated doses of cyclophosphamide and agents that can inhibit the formation and release of lysosomal enzymes and prostaglandins, may contribute to the failure of these drugs in some cases of RA.

If the inadequate fibrinolysis leading to fibrin deposits in the joints could be enhanced, it might result in clinical benefit to RA patients. A pilot study by Fearnley et al. ${ }^{5}$ in which RA patients were improved by fibrinolytic enhancing therapy would support this view. Work by Cunliffe et al. ${ }^{18}$ who used the same agent in vasculitis, also detected clinical improvement in the three patients with RA. We gave 12 patients with RA stanozolol, an anabolic steroid with fibrinolytic enhancing effects, to determine whether it was possible to stimulate fibrinolytic activity in this disease. A significant increase in blood PA activity was produced. In order to establish whether stanzolol could enhance fibrinolysis in the active site of the disease, that is, the joints, five patients received stanozolol with aspiration of knee joint effusion before and after. Results confirmed an increase in potential for joint fibrinolysis.

In conclusion we would suggest that inadequate fibrinolysis occurs in RA as measured by PA activity, and that this may contribute to the excess fibrin deposition in the joints, leading to some of the features of RA. In addition we have shown that the fibrinolytic enhancing agent stanozolol can increase plasma and joint fibrinolysis.

Theoretically it should therefore be possible to alleviate some of the symptoms of RA with these agents. A double-blind study to evaluate this hypothesis is under way.

\section{References}

1 Takeda Y. Studies of the metabolism and distribution of fibrinogen in patients with rheumatoid arthritis. J Lab Clin Med 1969; 69: 624-33.

2 Bach Andersen R, Gormsen J. Fibrinolytic and fibrin stabilizing activity of synovial membranes. Ann Rheum Dis 1976; 29: 287-93.

3 Van de Putte L B A, Kluft C, Noordhoek Hegt V, Wijngaards G. Haverkate F, Cats A. Activators and inhibitors of fibrinolysis in rheumatoid joint inflammation in: Willoughby D A, Giroud J P, Velo G P, eds. Perspectives in inflammation. Baltimore: University Park Press, 1977; 499-503.

4 Jasani, M K. Fibrin: metabolism, immunopathogenesis and significance in rheumatoid arthritis. In: Panayi G S, Johnson P M, eds. Immunopathogenesis of rheumatoid arthritis. Surrey: Reedbooks, 1978: 137-46.

5 Fearnley G R, Chakrabarti R, Evans J F. Fibrinolytic treatment of rheumatoid arthritis with phenformin plus ethyloestrenol. Lancet 1966; ii: 757-61.

6 Conn D L, McDuffie F C, Kazmier F J, Schroetter A L, Sun N C J. Coagulation abnormalities in rheumatoid disease. Arthritis Rheum 1976; 19: 1237-43.

7 Van de Putte L B A, Noordhoek Hegt V. Overbeck T E. Activators and inhibitors of fibrinolysis in rheumatoid and nonrheumatoid synovial membranes. Arthritis Rheum 1977; 20: 671-8.

8 Mallya R K, de Beer F C, Berry H, Hamilton E D B, Mace B E W, Pepys M B. Correlation of clinical parameters of disease activity in rheumatoid arthritis with serum concentration of C-reactive protein and erythrocyte sedimentation rate. $J$ Rheumatol 1982; 9: 224-8.

9 Clauss A. Gernnungs physiologische Schnellmethode zur Bestimmung des Fibrinogens. Acta Haematol 1957; 17: 237-51.

10 Alkajaersig N, Fletcher A P, Sherry S. The mechanism of clot dissolution by plasmin. $J$ Clin Invest 1959; 38: 1086-8.

11 Kluft C, Brakman P, Veldhuyzen-Stalk E C. Screening of the fibrinolytic activity in plasma euglobulin fractions on the fibrin plate. In: Davidson J F, Samana M M, Desnoyers P C eds. Progress in chemical fibrinolysis and thrombosis. New York: Raven press, 1976: 2: 57-65.

12 Mancini G, Carbonara A O, Heremans J F. Immunochemical quantitation of antigens by single radial immuno diffusion. Immunochemistry 1965; 2: 235-54.

13 Flory E D, Clarris B J, Muirden K D. Deposits of $\alpha_{2} \mathrm{M}$ in the rheumatoid synovial membrane. Ann Rheum Dis 1982; 41: $520-6$.

14 Hedner U, Nilsson I M. Antithrombin III as a clinical material. Thromb Res 1973; 3: 631-41.

15 Kwaan H C, Astrup T. Tissue repair in presence of locally applied inhibitors of fibrinolysis. Exp Mol Pathol 1969; 11: 82-7.

16 Berger H, Fleming P R, Voorhees P R. Secretion of plasminogen activator by rheumatoid and non-rheumatoid synovial cells in culture. Arthritis Rheum 1977; 20: 1198-205.

17 Dumonde D C, Glynn LE. The production of arthritis in rabbits by an immunological reaction to fibrin. Br J Exp Pathol 1962; 43: $373-8$.

18 Cunliffe W J, Dodman B, Roberts B E, Tebbs E M. Clinical and laboratory double-blind investigation of fibrinolytic therapy of cutaneous vasculitis. In: Davidson J D, Samama $\mathbf{M}$ M, Desnoyers P C, eds. Progress in chemical fibrinolysis and thrombolysis. New York: Raven Press, 1975: 1: 325-33. 